\author{
Military Technical College \\ Kobry El-Kobbah, \\ Cairo, Egypt.
}

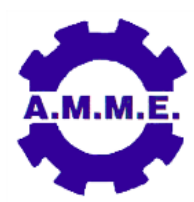

$17^{\text {th }}$ International Conference on Applied Mechanics and Mechanical Engineering.

\title{
DESIGN OF A COMBINED COOLING AND HEATING SYSTEM DRIVEN BY A BACK PRESSURE STEAM TURBINE IN BORG EL-ARAB
}

\author{
M. A. Nawar*, E. Elgendy* and A. Mostafa*
}

\begin{abstract}
ABSTARCT
In this paper, a combined cooling and heating system is designed to meet the cooling and heating demands for multipurpose applications by thermodynamic solar (MATS) project. Thermal power of $1 \mathrm{MW}$, cooling capacity of $300 \mathrm{~kW}$ and heating capacity of $300 \mathrm{~kW}$ are the project demands. Firstly, an optimization of the backpressure of the steam turbine is done based on the thermal power cycle efficiency and the cooling system driving energy. Results revealed that, a backpressure of 2.1 bar can achieve an optimum thermal power cycle efficiency of $24.57 \%$ with an optimum thermal energy to the absorption system of $98.6 \%$ from the maximum available. Then, a simulation analysis of the cooling and heating systems under climatic conditions of Borg El-Arab city is performed to estimate the required steam rate. Based on the simulation results, a steam mass flow rate of $0.622 \mathrm{~T} / \mathrm{h}$ is sufficient to drive the absorption system.
\end{abstract}

\section{KEY WORDS}

Combined cooling heating and power; Renewable energy; Backpressure turbine; Absorption chiller; trigeneration.

\footnotetext{
* Assistant Professor, Mechanical Power Engineering Department, Faculty of Engineering at El-Mattaria, Helwan University, Egypt.
} 


\section{NOMENCLATURE}

$\begin{array}{llll}\text { COP } & \text { coefficient of performance }(-) & \text { max } & \text { maximum } \\ \mathrm{Cp} & \text { specific heat at constant pressure } & \mathrm{o} & \text { outlet } \\ \mathrm{h} & \text { specific enthalpy }(\mathrm{kJ} \mathrm{kg}-1) & \mathrm{p} & \text { polytropic } \\ \dot{m} & \text { mass flow rate }(\mathrm{kg} \mathrm{s}-1) & \mathrm{r} & \text { ratio } \\ \mathrm{Q} & \text { heat transfer rate }(\mathrm{kW}) & \mathrm{ref} & \text { refrigerant } \\ \mathrm{T} & \text { temperature }\left({ }^{\circ} \mathrm{C}\right) & \mathrm{Sh} & \text { solution heat exchanger } \\ \mathrm{X} & \text { concentration } & \text { st } & \text { steam } \\ \mathrm{P} & \text { power } & \mathrm{v} & \text { saturated vapor } \\ \mathrm{p} & \text { pressure } & \mathrm{w} & \text { water } \\ & & \text { wb } & \text { wet bulb } \\ \text { GREEK SYMBOLS } & & \\ \gamma & \text { specific heat ratio } & \text { ws } & \text { weak solution } \\ \varepsilon & \text { effectiveness } & \text { ss } & \text { strong solution } \\ \eta & \text { efficiency } & \text { th } & \text { thermal }\end{array}$

\begin{tabular}{ll}
\multicolumn{2}{l}{ SUBSCRIPTS } \\
a & absorber \\
$\mathrm{c}$ & condenser \\
& \\
$\mathrm{e}$ & evaporator \\
$\mathrm{f}$ & saturated liquid \\
$\mathrm{g}$ & generator \\
$\mathrm{h}$ & heat exchanger \\
$\mathrm{i}$ & inlet \\
is & isentropic
\end{tabular}

$\begin{array}{ll}\text { ABBREVIATIONS } \\ \text { CHP } & \text { combined heating and power } \\ \text { CCHP } & \begin{array}{l}\text { combined cooling, heating and } \\ \text { power }\end{array} \\ \text { MATS } & \begin{array}{l}\text { multipurpose applications by } \\ \text { thermodynamic solar }\end{array} \\ \text { RH } & \begin{array}{l}\text { reheat factor } \\ \text { VARS }\end{array} \\ & \begin{array}{l}\text { vapor absorption refrigeration } \\ \text { system }\end{array}\end{array}$

\section{INTRODUCTION}

The well-known energy problem due to the unstable oil price, uncertain reserves capacity and environmental pollution problems, is stimulating the development of clean innovative technologies. The exploitation of renewable energy resources for heat and power production is commonly considered the most promising way to reduce the impact of human activities on environment. Typically, combined heating and power (CHP) systems are defined as the combined production of electrical (or mechanical), and useful thermal energy from the same primary energy source [1-2] while combined cooling, heating and power (CCHP) systems are referred to trigeneration systems such as building cooling, heating and power [3].

CCHP systems consist of five basic elements; a prime mover, an electricity generator, a heat recovery equipment, a thermally activated equipment and management and control devices. In terms of rated sizes, CCHP systems are categorized into micro, small, medium and large scale systems with ranges under $20 \mathrm{~kW}$, from $20 \mathrm{~kW}$ to $1 \mathrm{MW}$, from 1 to $10 \mathrm{MW}$ and above 10MW, respectively[4]. An optimal operation strategy based on the relationship between energy load and full capacity output of power generation unit is designed for the CCHP system. Reported results showed that, the optimized structured CCHP system can achieve higher performance than the 
conventional system. Moreover, the annual cost of the CCHP system is reduced more than half of that of the conventional system [5].

Recently, a new CCHP driven by solar energy and biomass resources are used to reduce fossil fuel consumption and alleviate environmental problems [6-10]. A performance assessment of a CCHP system running with both methanol and solar energy was investigated by Li et al. [11].The overall energy efficiency of the CCHP system ranged from $40 \%$ to $50 \%$ in summer conditions, and $38 \%$ to $47 \%$ in winter conditions. A comprehensive performance assessment for a CCHP system was presented in a data center. The assessment was supported by actual site operational data and transient modeling in TRNSYS. Energy, environmental and economic metrics were defined to assess the overall performance of CCHP systems [12].In addition, comprehensive thermodynamic studies were undertaken to produce multiple commodities of a multigeneration system for residential applications [13-16].

In the present paper, a medium scale CCHP is designed as a part of multipurpose applications by thermodynamic solar (MATS) project. The CCHP system is driven by a steam turbine. Hence, a steam turbine backpressure is optimized based on the requirements of both the power and cooling demands. Based on the optimum backpressure, a theoretical analysis of cooling and heating system under identical weather data of Borg El-Arab city is investigated to estimate the required steam rate.

\section{SYSTEM DESCRIPTION}

Figure 1 shows the outline of MATS project. The project aims at promoting the exploitation of concentrated solar energy through small and middle scale facilities, suitable to fulfill local requirements of power and heat, and easily to back-up with the renewable fuels locally already available or that can be expressly produced. The MATS project is focused on the innovative concentrating solar power (CSP) technology developed by ENEA as an improvement of its solar thermodynamic technology based on molten salts as heat transfer fluid. This technology allows combined heat and power production from solar source integrated with renewable fuels, such as biomass, biogas, industrial residues etc. by means of standardized units that provide high performances and limited cost. The thermal energy produced by this plant will be used as energy source in a desalination unit included in the installation, as well as for district heating and cooling. The use of suitable heat storage systems enhance mismatch of power production from the instantaneous solar radiation availability. These features enable electrical energy production "on demand" and the optimized utilization of captured solar heat by additional loads like desalination units. The integration with a back up fuel like biomass makes the system flexible and enables continuous power production.

A typical CCHP system is showed in Fig. 2. It is comprised of a steam turbine, a generator, a vapor absorption refrigeration system (VARS) and a water heater. The steam turbine is driven by the produced steam from concentrating solar collectors and the mechanical energy is further changed into electricity power by the generator.

At the same time, the VARS and the water heater are used to generate cooling and heating demands using steam exit from the turbine. Thus, the energy demands of cooling, heating and electrical power in a building or a district can be met by this system 


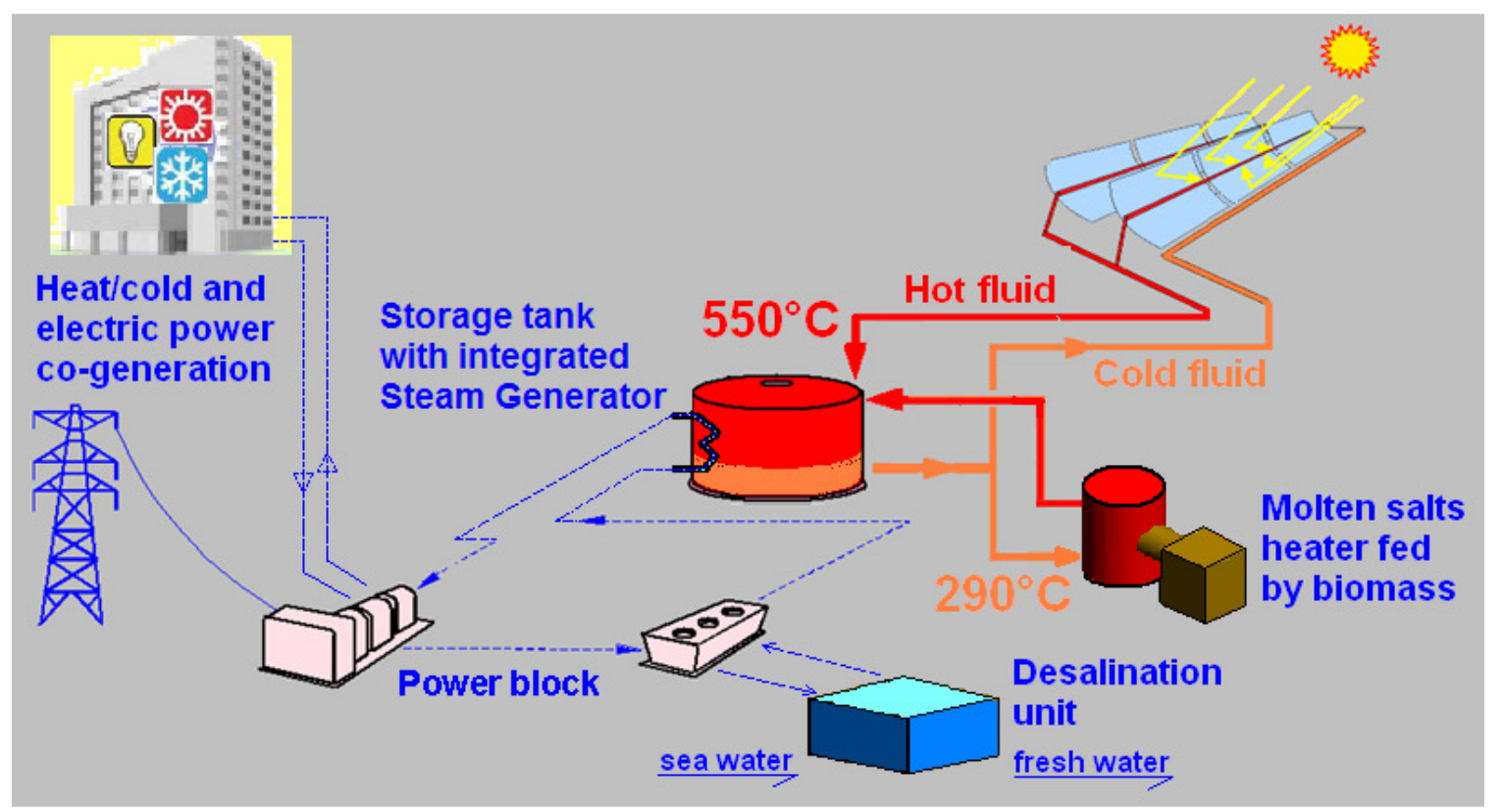

Fig. 1. Outline of MATS project.

simultaneously. The plant target is to generate thermal power, heating and cooling capacities of $1 \mathrm{MW}, 300 \mathrm{~kW}$ and $300 \mathrm{~kW}$ respectively.

The CCHP system contains three fluid circuits namely driving fluid circuit, absorption refrigeration circuit and cooling water circuit.In the driving fluid circuit (state points 1:4), the generated steam from the solar field sub-system is supplied to the steam turbine $\left(60\right.$ bar and $500^{\circ} \mathrm{C}$ ) to produce the required electric power. Then the backpressure steam flows through the generator of a water-lithium bromide single effect VARS circuit to produce the required cooling capacity. Then, the driving fluid passes through the water heater to produce the required hot water for heating demand before it returns back to the solar field sub-system.

The second circuit is a single effect VARS (state points 5:14). The refrigerant (water) flows in the left cycle (state points 11:14) while the solution (water-lithium bromide) flows in the right cycle (state points 5:10). The VARS consists of a generator, an absorber, a condenser and an evaporator, a solution heat exchanger, a solution pump and expansion valves. The saturated water vapor exits from evaporator (state point 14) flows to the absorber to mix with the strong solution coming from the solution expansion device (state point 10). Then, a weak concentration of water-lithium bromide is formed (state point 5) and pumped to the solution heat exchanger via a solution pump. The weak solution is then heated (state points 6-7) by the transferred heat from the strong solution, (state points 8-9).

In the generator, a saturated water vapor is formed and flowed to the condenser (state point 11) while the strong solution is passed through the solution heat exchanger (state point 8). The strong solution transferred its heat to the weak solution in the liquid heat exchanger and then mix with the saturated water vapor in its pressure is reduced in the solution expansion device. The saturated water vapor coming from the generator 


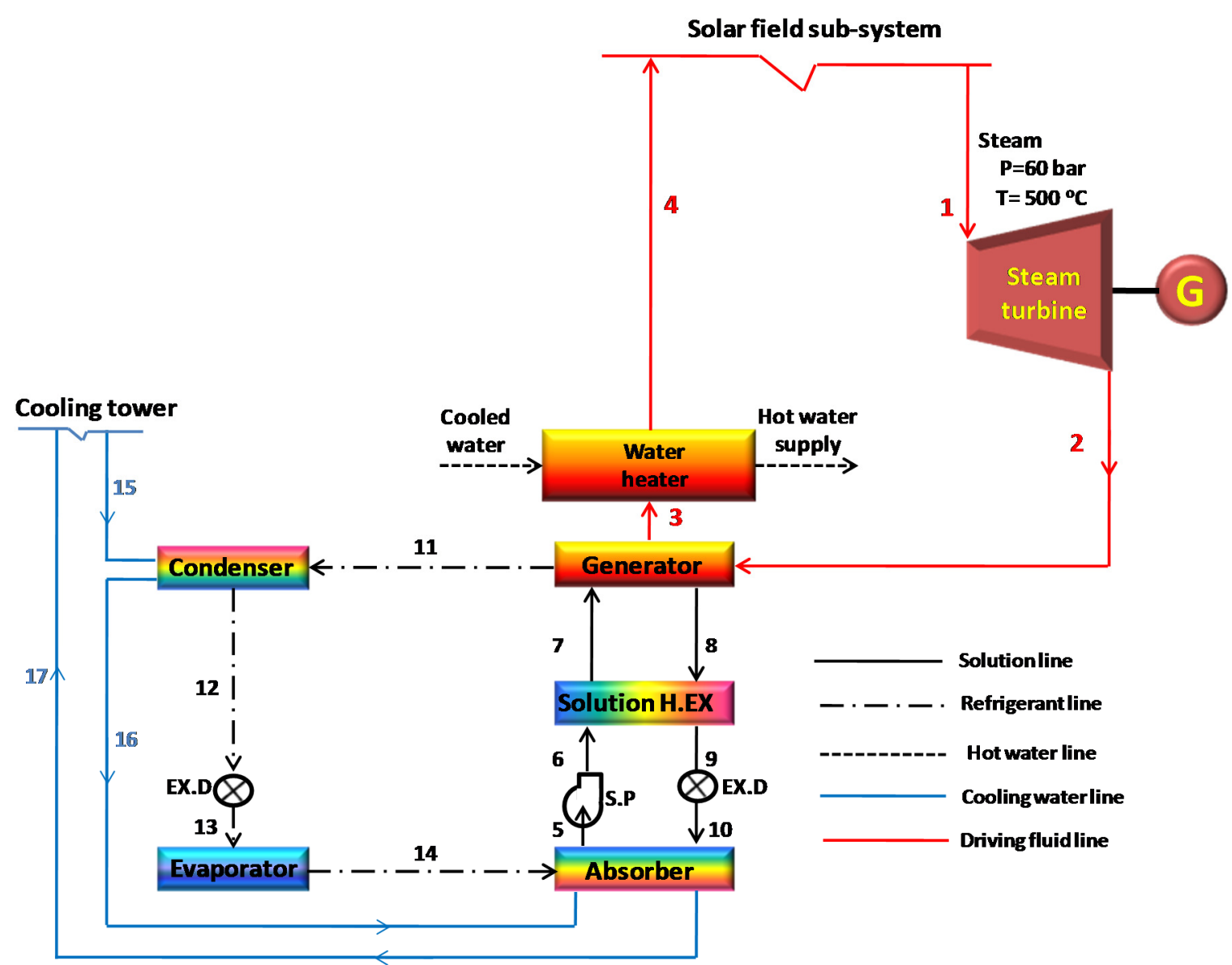

Fig. 2. Schematic diagram of the CCHP plant.

is converted into saturated liquid in the absorber after the condenser by transferred its heat to the cooling water circuit. The pressure of the saturated liquid exits from the condenser is reduced in the refrigerant expansion device and then flows to the evaporator. The heat rejected at absorber and condenser is dissipated to the ambient using the cooling water circuit (state points 15:17). It should be noted that, the cooling water flows firstly to the condenser (state point 15) and then through the absorber (state point 16). The exits cooling water from the absorber (state point 17)is cooled in the cooling tower.

\section{METHODOLOGY}

In fact, design of the CCHP system is constrained with inputs from the whole plant and has a specific target. The main input data are the temperature and pressure of the delivered steam from the solar field which are 60 bar and $500^{\circ} \mathrm{C}$. However, the main targets are to produce a thermal power of $1 \mathrm{MW}, 300 \mathrm{~kW}$ cooling at $2^{\circ} \mathrm{C}$ evaporator temperature and heating power of $300 \mathrm{~kW}$. Firstly, the steam turbine back pressure is optimizing to get the thermal power cycle efficiency and driving energy of the VARS. Then, a theoretical study to the performance characteristics of the VARS with a fixed cooling capacity of $300 \mathrm{~kW}$ and under climatic conditions of Borg El-Arab city is 
performed to get the required steam rate. Finally, the performance characteristics of the heating system are investigated around the year to estimate the produced hot water supply.

\section{Optimum Steam Turbine Back Pressure}

The steam backpressure is an important parameter that affects the performance and efficiency of both, the backpressure steam turbine and the VARS. The steam turbine inlet conditions are $500^{\circ} \mathrm{C}$ and 60 bar, and the exit conditions are dry saturated steam with a minimum saturation temperature of $100^{\circ} \mathrm{C}(1 \mathrm{bar})$. The backpressure affects the various parameters belonged to the turbine performance. Such parameters are saturation temperature that corresponding to backpressure, required steam mass flow rate, specific enthalpy of exhausted steam, turbine polytropic and isentropic efficiencies and reheat factor of the turbine expansion as follows:

$$
\begin{gathered}
\mathrm{p}_{\mathrm{r}}=\frac{\mathrm{p}_{1}}{\mathrm{p}_{2}} \\
\dot{\mathrm{m}}_{\mathrm{st}}=\frac{\mathrm{P}}{\mathrm{h}_{1}-\mathrm{h}_{2}} \\
\mathrm{~h}_{2}=\mathrm{h}_{\mathrm{v}} \text { at corresponding } \mathrm{p}_{2} \\
\mathrm{Q}_{\mathrm{th}}=\mathrm{h}_{\mathrm{fv}} \text { at corresponding } \mathrm{p}_{2} \\
\eta_{\mathrm{th}}=\frac{\mathrm{h}_{1}-\mathrm{h}_{2}}{\mathrm{~h}_{1}-\mathrm{h}_{\mathrm{f}}} \\
\eta_{\mathrm{p}}=\frac{\ln \left(1-\frac{\mathrm{p}}{\mathrm{m} * \mathrm{C}_{\mathrm{p}} * \mathrm{~T}_{1}}\right)}{\ln \mathrm{p}_{\mathrm{r}} *\left(\frac{1-\gamma}{\gamma}\right)} \\
\eta_{\text {is }}=\frac{1-\mathrm{p}_{\mathrm{r}} \frac{(1-\gamma) \eta_{\mathrm{p}}}{\gamma}}{1-\mathrm{p}_{\mathrm{r}}^{\frac{(1-\gamma)}{\gamma}}} \\
\mathrm{RH}=\frac{\eta_{\mathrm{is}}}{\eta_{\mathrm{p}}}
\end{gathered}
$$




\section{Vapor Absorption Refrigeration System (VARS)}

Evaporator, condenser, absorber, and generator temperatures represent the operating temperatures of VARS. The evaporator temperature is $2^{\circ} \mathrm{C}$ according to the requirement of the MATS project and the condenser temperature is calculated based on the wet bulb temperature of the ambient air. The absorber temperature is higher than condenser temperature due to the series connections of condenser and absorber cooling water. The generator temperature is assumed equal to the saturated temperature corresponding to the optimum steam turbine back pressure. Hence, the operating temperatures are calculated as the following;

$$
\begin{gathered}
T_{5}=T_{6}=T_{a}=T_{c}+\Delta t \\
T_{12}=T_{c}=T_{w b}+\Delta t \\
T_{14}=T_{e} \\
T_{8}=T_{11}=T_{g}
\end{gathered}
$$

Temperature of the strong solution exit from the solution heat exchanger $\left(T_{9}\right)$ is calculated as the following;

$$
T_{9}=T_{10}=T_{8}-\varepsilon_{h}\left(T_{8}-T_{6}\right)
$$

where the solution heat exchanger effectiveness $\left(\varepsilon_{h}\right)$ is constant and equal to 0.85. Thus, temperatures at all state points for both refrigerant and solution circuits are determined. The strong and weak solution concentrations can be determined as a function of operating temperatures in the solution circuit. Since there would be no concentration changes in pumping and expansion processes or in the solution heat exchanger, the following equations are possible;

$$
\begin{aligned}
& X_{w s}=X_{5}=X_{6}=X_{7} \\
& X_{s s}=X_{8}=X_{9}=X_{10}
\end{aligned}
$$

The mass flow rate of refrigerant $\dot{m}_{\text {ref }}$ can be determined through an energy balance on the evaporator, i.e.

$$
\dot{m}_{r e f}=\frac{Q_{e}}{h_{14}-h_{13}}
$$


Mass flow rates of weak and strong solutions are obtained as:

$$
\dot{m}_{w s}=\dot{m}_{7}=\dot{m}_{r e f} \frac{1-X_{w s}}{X_{w s}-X_{s s}}
$$

and

$$
\dot{m}_{s s}=\dot{m}_{w s}-\dot{m}_{r e f}
$$

Energy balance is applied for each component to calculate its load as given;

- Condenser heat rejected

$$
Q_{c}=\dot{m}_{r e f}\left(h_{11}-h_{12}\right)
$$

- Generator heat input

$$
Q_{g}=\dot{m}_{r e f} h_{11}+\dot{m}_{s s} h_{8}-\dot{m}_{w s} h_{7}
$$

- Absorber heat rejected

$$
Q_{a}=\dot{m}_{r e f} h_{14}+\dot{m}_{s s} h_{10}-\dot{m}_{w s} h_{5}
$$

The thermal coefficient of performance $\left(\mathrm{COP}_{\text {th }}\right)$ of VARS is defined as the ratio of cooling capacity at evaporator and heat input to generator, i.e.

$$
C O P_{t h}=\frac{Q_{e}}{Q_{g}}
$$

\section{Heating System}

A heat exchanger is inserted in the system to provide a hot water for household applications by using the back pressure steam after the generator of the VARS. Assuming the water inlet temperature to the heat exchanger equal the ambient wet bulb temperature, the exit water temperature from the heat exchanger can be calculated as follows;

$$
Q_{h}=\dot{m}_{w} * C_{w}\left(T_{w, i}-T_{w, o}\right)
$$

\section{RESULTS AND DISCUSSION}

In order to design the CCHP system according to the power, cooling and heating demands an optimization process of the backpressure of the steam turbine is 
performed. Using the optimum backpressure and the required cooling demand $(300 \mathrm{~kW})$ as input for a simulation program under the climatic conditions of Borg $\mathrm{El}-$ Arab city, the required steam mass flow rate for the VARS is estimated.

\section{Optimum Steam Back Pressure}

Definitely, the inlet conditions of the steam turbine (pressure and temperature) and the required steam mass flow rate (dry saturated) for the absorption system are the key factors in determining the appropriate steam back pressure. The temperature of backpressure steam represents the generator temperature in the absorption refrigeration system, where the latent heat is the source of the thermal energy required to drive the generator. The steam turbine inlet conditions are $500^{\circ} \mathrm{C}$ and $60 \mathrm{bar}$, and the absorption refrigeration system inlet conditions are dry saturated steam with a minimum saturation temperature of $100^{\circ} \mathrm{C}(1 \mathrm{bar})$. Hence, it is very important to detect carefully the optimum backpressure value and its corresponding temperature to maximize steam utility which can serve the two sub-systems simultaneously.

Figure 3 demonstrates the effect of backpressure on the thermal power cycle efficiency ratio and thermal energy ratio for the VARS. Thermal power cycle ratio is the ratio between the thermal power cycle efficiency to the maximum possible efficiency at minimum backpressure of 1 bar (minimum required pressure for the VARS). However, the thermal energy ratio is the ratio between thermal energy to the maximum thermal available energy at 4.2 bar where an isentropic expansion takes place. Increasing the turbine backpressure increases the thermal available energy to the VARS, but reduces the thermal power cycle efficiency. In contrast happens when backpressure is reduced. The intersection point indicates the optimum value of the backpressure at 2.1bar, which gives thermal energy ratio of approximately 98.6\% (3069.4 kW) and thermal power cycle efficiency ratio of $98.6 \%$ (24.57\%).

Figure 4 illustrates the relation between the backpressure and the steam turbine performance parameters. Increasing the turbine backpressure increases the turbine isentropic and polytropic efficiencies and the steam mass flow rate. Accordingly, the optimum backpressure lies at 2.1 bar. The corresponding values of saturation temperature, steam mass flow rate required, specific enthalpy of exhausted steam, polytropic and isentropic efficiencies are $122^{\circ} \mathrm{C}, 5.03 \mathrm{~T} / \mathrm{h}$., $2710 \mathrm{~kJ} / \mathrm{kg}, 84.7 \%$ and 89.5 $\%$ respectively as shown in Fig. 4.

Reheat factor is a measure of the inefficiency of the steam turbine expansion because vapor does not obey the perfect gas laws. The reheat factor value will depend upon the steam conditions at turbine inlet and outlet and the pressure ratio of the expansion. In normal steam turbine practice, the reheat factor value is usually between 1.03 and 1.08 [17]. The equivalent reheat factor for the steam turbine expansion at the optimum backpressure value of 2.1 bar is 1.057 . 


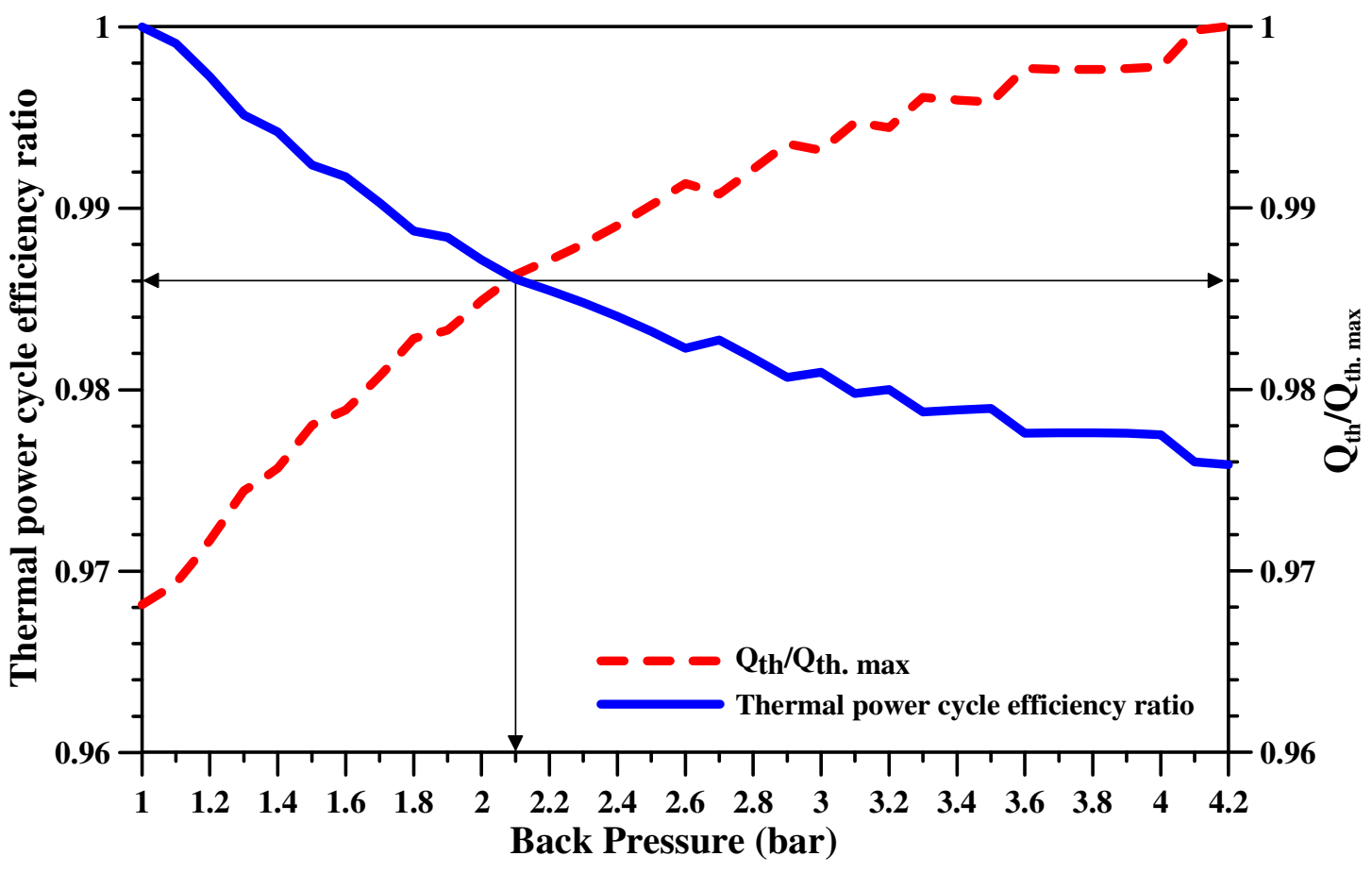

Fig. 3. Effect of back pressure on the thermal power cycle efficiency ratio and thermal energy ratio for the VARS.

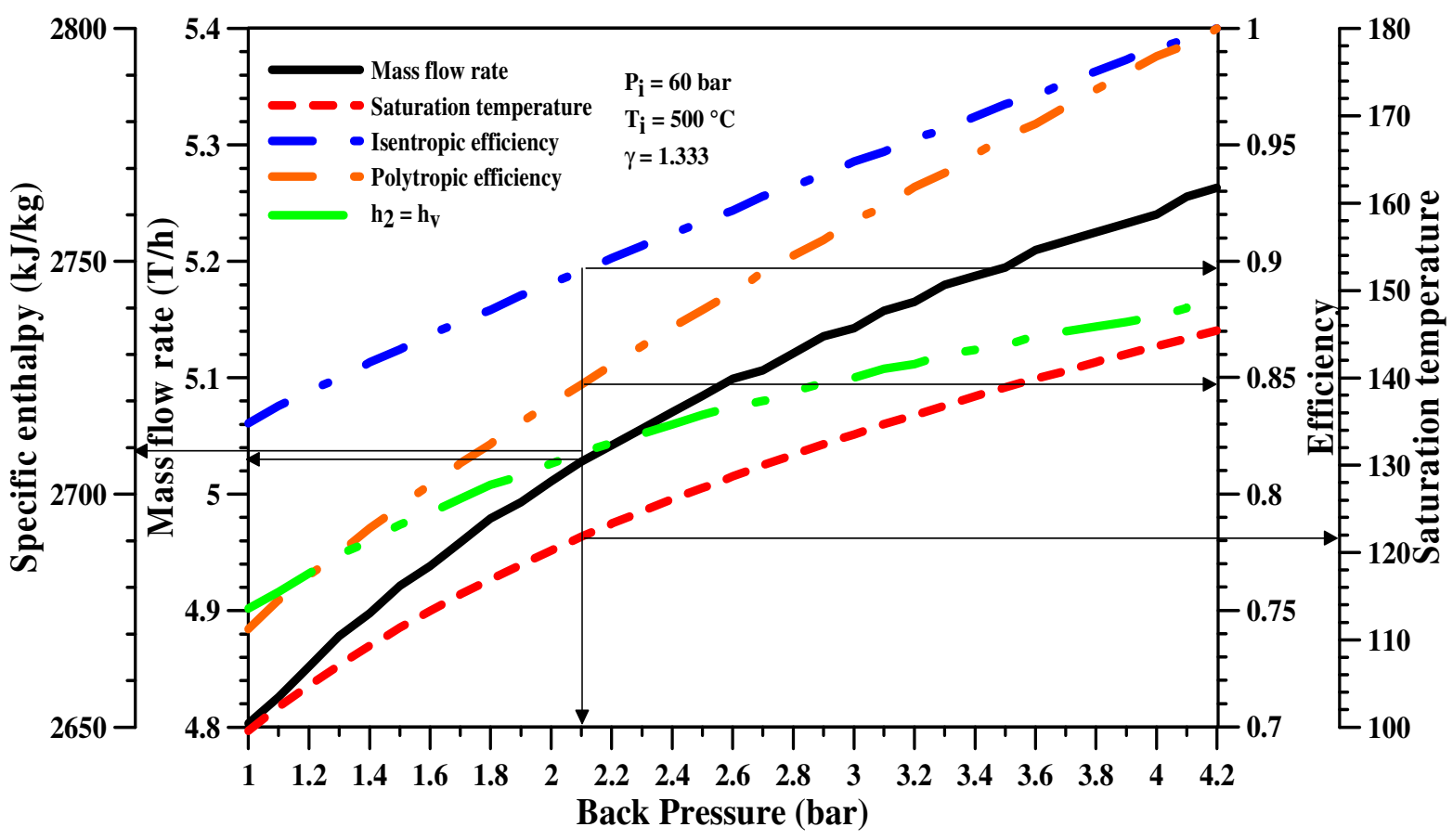

Fig. 4. Effect of back pressure on performance characteristics of $1 \mathrm{MW}$ steam turbine. 


\section{Cooling System Performance}

VARSis a heat driven system at moderate temperature and is usually coupled with solar collector or waste heat supplier. This system results in a great economy in electrical energy, mainly in places where thermal energy resources are available.

The performance of VARS is very sensitive to outside conditions, source temperature and effectiveness of the system components. The effect of climatic conditions of Borg El-Arab city is obtained on the VARS at constant source temperature of $121^{\circ} \mathrm{C}$ (steam saturated temperature corresponding to pressure 2.1bar). Variation of operating temperatures, refrigerant mass flow rate, heat loads, thermal coefficient of performance and steam mass flow rate are discussed.

Figure 5 shows variation of dry bulb temperature for Borg El-Arab city with year months. It can be seen that the dry bulb temperature increases to a maximum value in August and then decreases. Also, the dry bulb temperature is higher than the human comfort temperature from April to November. Hence, there is a need for the cooling process during that time period.

It should be mentioned that, VARS can be classified to a single effect or double effect absorption chiller. The double effect VARS has a higher coefficient of performance (0.8-1.2) than that of single effect (0.6-0.8), but it is required a higher temperature source than that of a single effect. The variation of minimum required generator temperature for single and double effect VARS under climatic conditions of Borg ElArab city with month is presented in Fig. 6. Clearly, the minimum generator temperature for both systems has the same behavior of ambient temperature, which increases to a maximum value in August and then decreases. The maximum value of minimum generator temperature for double and single effect VARS is $142^{\circ} \mathrm{C}$ and 104 ${ }^{\circ} \mathrm{C}$, respectively. The minimum generator temperature for double effect VARS is higher than the available source temperature in most months of the year. Hence, a single effect VARS is the appropriate system according to the available heat source temperature.

Figure 7 illustrates variation of condenser, absorber and generator heat loads with year months. Results reveal that the maximum valuesof condenser, absorber and generator loads in August are 324.8, 363.9 and $379.3 \mathrm{~kW}$, respectively. Also, the percentage increase of condenser, absorber and generator heat loads from minimum value in April up to August are $1.53 \%, 4.88 \%$ and $4.83 \%$, respectively.

The behavior of $\mathrm{COP}_{\text {th }}$ and steam mass flow rate during the considered period with month is presented in Fig. 8. The required steam mass flow rate increases with month to a maximum value of $0.6202 \mathrm{~T} / \mathrm{h}$ in August and then decreases, while the $\mathrm{COP}_{\text {th }}$ decreases from a maximum value in April of 0.829 to a minimum value of 0.791 in August.

\section{Heating System Performance}

Figure 9 depicts the effect of hot water mass flow rate on its exit temperature per month for the required heating load of $300 \mathrm{~kW}$. The figure shows that, at optimum hot water 


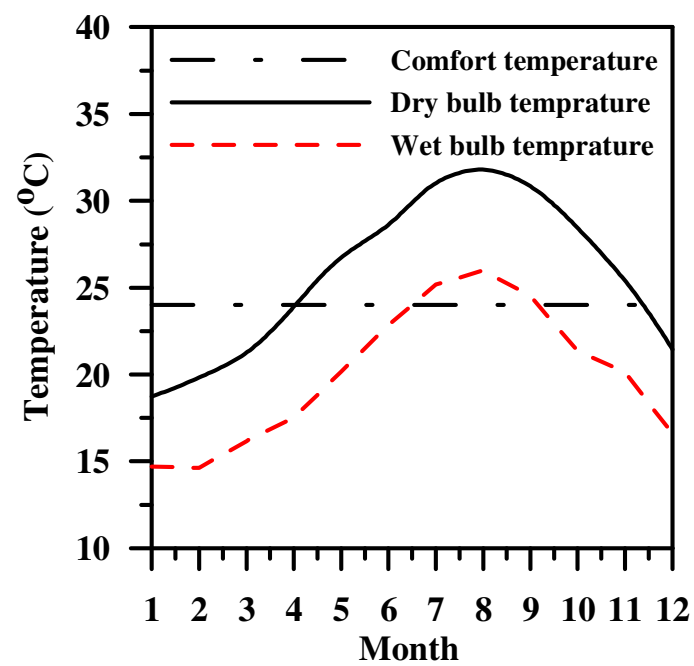

Fig. 5. Variation of dry and wet bulb temperatures with months.

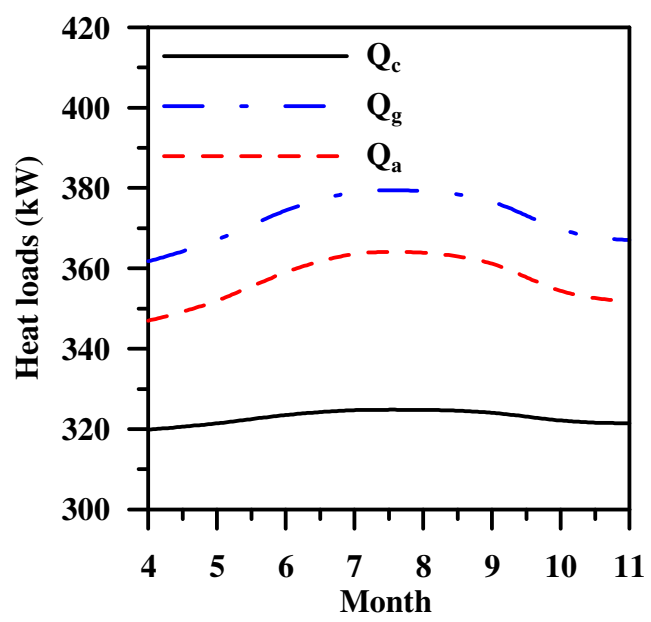

Fig. 7. Variation of condenser, absorber and generator loads with months.

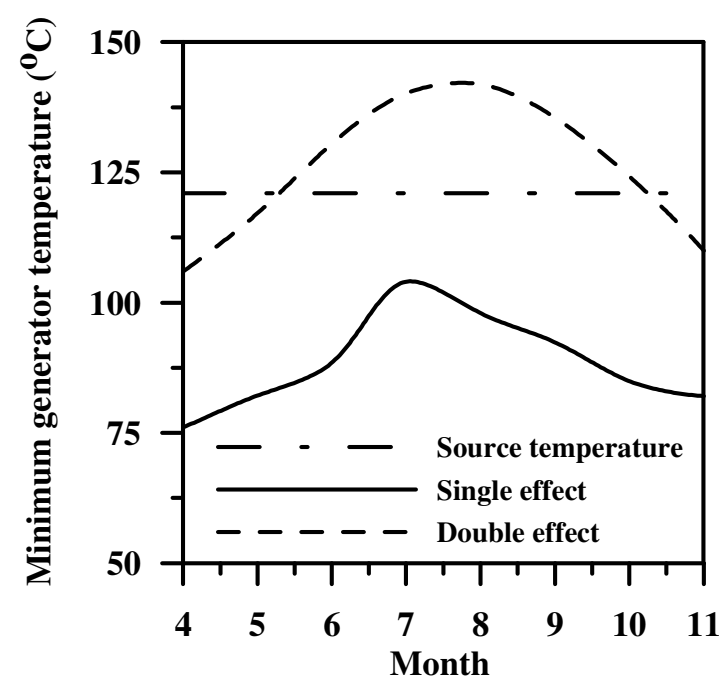

Fig. 6. Variation of minimum generator temperature with months.

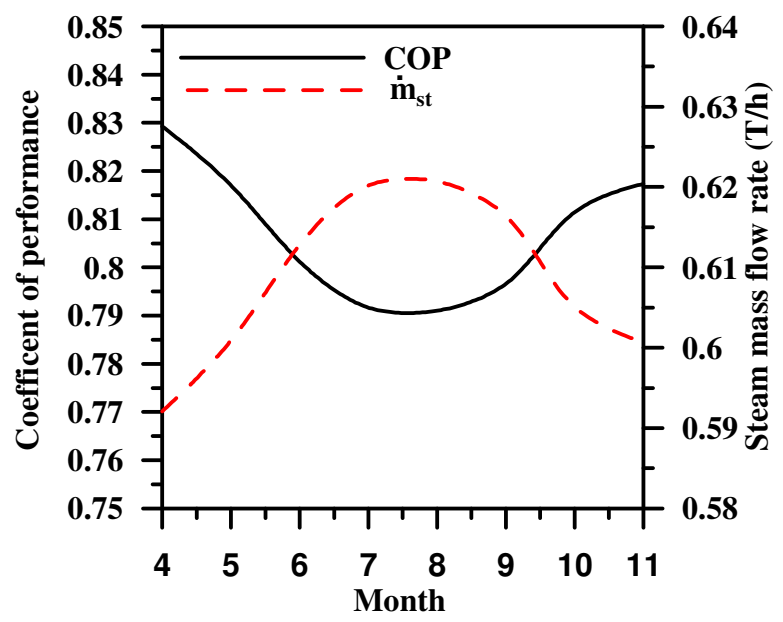

Fig. 8. Variation of COP and steam mass flow rate with months.

exit temperature of $55^{\circ} \mathrm{C}$, maximum hot water mass flow rate required is $6.6 \mathrm{~T} / \mathrm{h}$. If the hot water mass flow rate exceeds this value, especially in January, the hot water exit temperature will drop under the optimum value of $55^{\circ} \mathrm{C}$. Hence, the heating process will not be sufficient. On the other side, the hot water exit temperature in August reaches $65^{\circ} \mathrm{C}$ at the specified maximum hot water mass flow rate $(6.6 \mathrm{~T} / \mathrm{h})$. Thus, for $300 \mathrm{~kW}$ heating load, the minimum hot water temperature required for domestic and industrial applications can be achieved by a hot water mass flow rate not exceeds 6.6 $\mathrm{T} / \mathrm{h}$ along the year. 


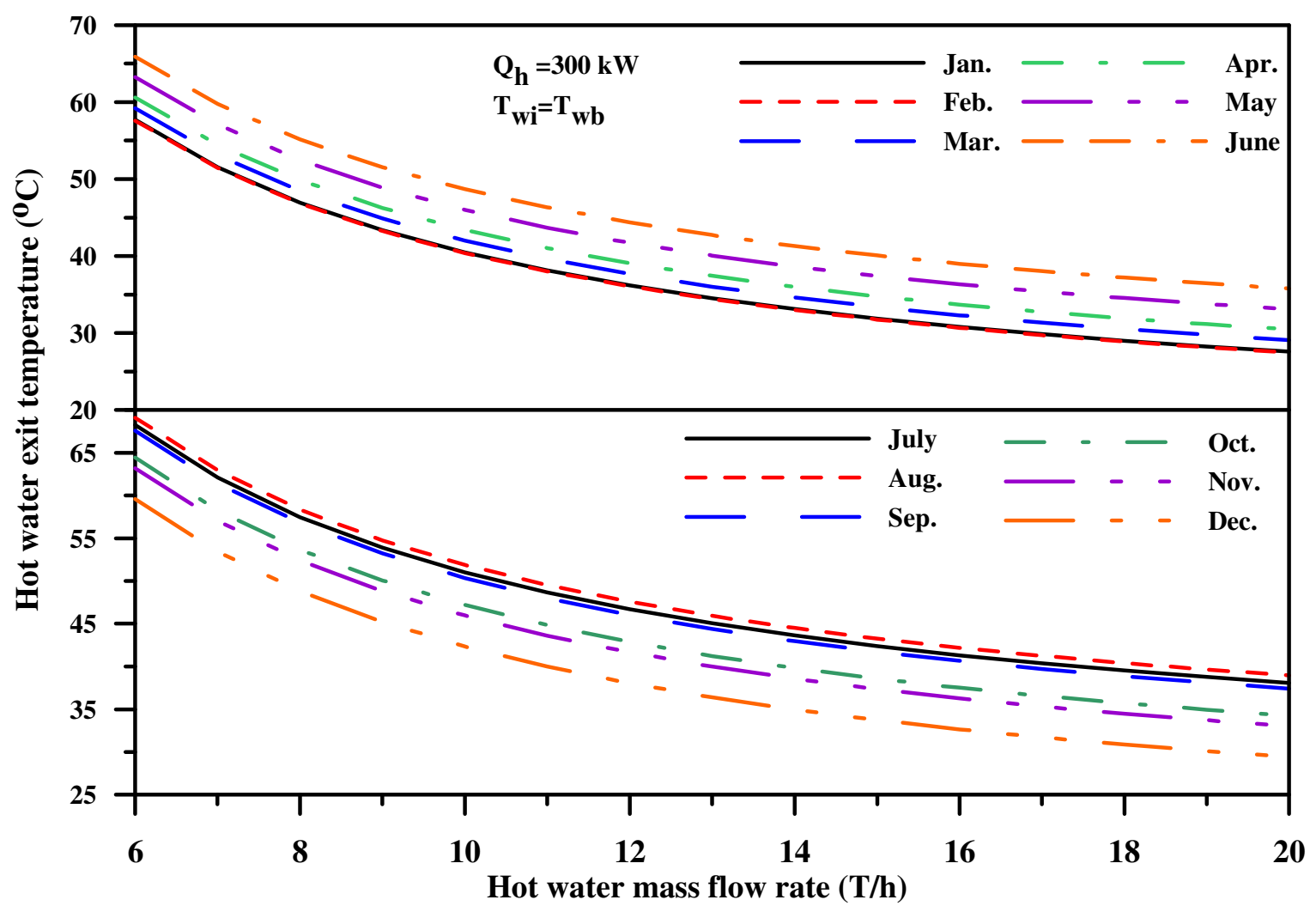

Fig. 9. Variation of exit hot water temperature with water mass flow rate for year months.

\section{CONCLUSION}

In this paper, a design procedure of a CCHP system is introduced as a part of "Multipurpose application by thermodynamic solar project" (MATS) project. Based on the reported results, the following conclusions are drawn:

- As the steam turbine backpressure increases the thermal power cycle efficiency decreases while the thermal energy ratio available to the cooling system increases.

- An optimum steam turbine backpressure of 2.1 bar is obtained which achieves a thermal power cycle efficiency of $24.57 \%$ with a driving energy rate to the VARS of $3069.4 \mathrm{~kW}$.

- The required steam flow rate for the cooling demands is $0.622 \mathrm{~T} / \mathrm{h}$ based on the simulation results under the climatic conditions of Borg El-Arab city.

\section{ACKNOWLEDGMENT}

This research was done under the scientific coordination of the Egyptian Academy of Scientific Research and Technology. It is part of the "Multipurpose application by thermodynamic solar project" (MATS) which is funded by European Commission under FP7 grant agreement number 268219. 


\section{REFERENCES}

[1] M.A. Ehyaei, A. Mozafari, A. Ahmadi, P. Esmaili, M. Shayesteh, M. Sarkhosh AND I. Dincer, "Potential use of cold thermal energy storage systems for better efficiency and cost effectiveness", Energy and Buildings, Vol. 42, pp. 2296-2303, 2010.

[2] C. A. Gibson, M. A. Meybodi and M. Behnia, "Optimization and selection of a steam turbine for a large scale industrial CHP (combined heat and power) system under Australia's carbon price", Energy, Vol. 61, pp. 291-307, 2013.

[3] G. Abdollahi and M. Meratizaman, "Multi-objective approach in thermo environomic optimization of a small-scale distributed CCHP system with risk analysis", Energy and Buildings, Vol. 43, pp. 3144-3153, 2011.

[4] T. Ackermann, G. Andersson and L. Söder, "Distributed generation: a definition", Electric Power Syst Res, Vol. 57, pp. 195-204, 2001.

[5] M. Liu, Y. Shi and F. Fang, "A new operation strategy for CCHP systems with hybrid chillers", Applied Energy, Vol. 95, pp. 164-173, 2012.

[6] I. Sarbu and C. Sebarchievici, "Review of solar refrigeration and cooling systems", Energy and Buildings, Vol. 67, pp. 286-297, 2013.

[7] J. Wang, P. Zhao, X. Niu and Y. Dai, "Parametric analysis of a new combined cooling, heating and power system with trans critical $\mathrm{CO} 2$ driven by solar energy", Applied Energy, Vol. 94, pp. 58-64, 2012.

[8] J. Wang, Y. Dai, L. Gao and S. Mab, "A new combined cooling, heating and power system driven by solar energy", Renewable Energy, Vol. 34, pp. 2780-2788, 2009.

[9] D. Maraver, A. Sin, J. Royo and F. Sebastián, "Assessment of CCHP systems based on biomass combustion for small-scale applications through a review of the technology and analysis of energy efficiency parameters", Applied Energy, Vol. 102, pp. 1303-1313, 2013.

[10] D. Maraver, A. Sin, F. Sebastián and J. Royo, "Environmental assessment of CCHP (combined cooling heating and power) systems based on biomass combustion in comparison to conventional generation", Energy, Vol. 57, pp. 17-23, 2013.

[11] S. Li, J. Sui, H. Jin and J. Zheng, "Full chain energy performance for a combined cooling, heating and power system running with methanol and solar energy", Applied Energy, Vol. 112, pp. 673-681, 2013.

[12] D. Xu and M. Qu, "Energy, environmental, and economic evaluation of a CCHP system for a data center based on operational data", Energy and Buildings, Vol. 67, pp. 176-186, 2013.

[13] P. Ahmadi, I. Dincer and M. A. Rosen, "Performance assessment and optimization of a novel integrated multigeneration system for residential buildings", Energy and Buildings, Vol. 67, pp. 568-578, 2013.

[14] A. Mammoli, P. Vorobieff, H. Barsun, R. Burnett and D. Fisher, "Energetic, economic and environmental performance of a solar-thermal-assisted HVAC system", Energy and Buildings, Vol. 42, pp. 1524-1535, 2010.

[15] M. Ortiz, H. Barsun, H. He, P. Vorobieff and A. Mammoli, "Modeling of a solar-assisted HVAC system with thermal storage", Energy and Buildings, Vol. 42, pp. 500-509, 2010.

[16] P. Ahmadi, I. Dincer and M. A. Rosen, "Thermodynamic modeling and multiobjective evolutionary-based optimization of a new multigeneration energy system", Energy Conversion and Management, Vol. 76, pp. 282-300, 2013. 
[17] S.L. Dixon and C.A. Hall, "Fluid Mechanics and Thermodynamics of Turbomachinery", $6^{\text {th }}$ Edition, Elsevier Inc., (2010). 